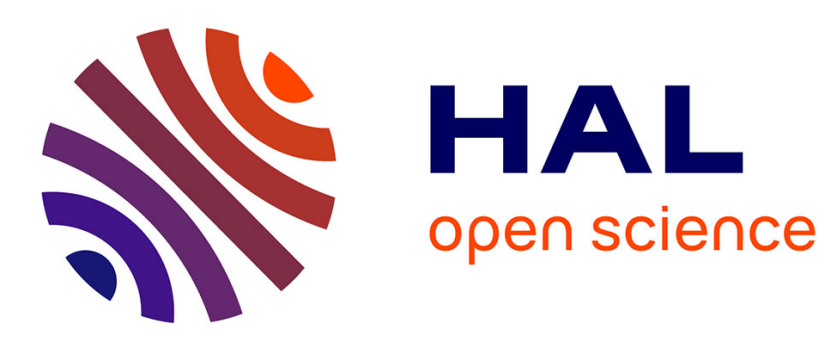

\title{
Analyzing risky behavior of motorists during the closure cycle of railway level crossings
}

\author{
Ci Liang, Mohamed Ghazel, Olivier Cazier, El Miloudi El Koursi
}

\section{To cite this version:}

Ci Liang, Mohamed Ghazel, Olivier Cazier, El Miloudi El Koursi. Analyzing risky behavior of motorists during the closure cycle of railway level crossings. Safety science, 2018, 110, pp115-126. 10.1016/j.ssci.2017.12.008 . hal-01757298

\section{HAL Id: hal-01757298 \\ https://hal.science/hal-01757298}

Submitted on 5 Feb 2020

HAL is a multi-disciplinary open access archive for the deposit and dissemination of scientific research documents, whether they are published or not. The documents may come from teaching and research institutions in France or abroad, or from public or private research centers.
L'archive ouverte pluridisciplinaire HAL, est destinée au dépôt et à la diffusion de documents scientifiques de niveau recherche, publiés ou non, émanant des établissements d'enseignement et de recherche français ou étrangers, des laboratoires publics ou privés. 


\title{
Analyzing risky behavior of motorists during the closure cycle of railway level crossings
}

\author{
Ci Liang ${ }^{\mathrm{a}, \mathrm{b}, \mathrm{c},}$, Mohamed Ghazel ${ }^{\mathrm{b}, \mathrm{a}, \mathrm{c}}$, Olivier Cazier ${ }^{\mathrm{d}, \mathrm{a}}$, El-Miloudi El-Koursi ${ }^{\mathrm{b}, \mathrm{a}, \mathrm{c}}$ \\ ${ }^{a}$ FCS Railenium, Valenciennes, France \\ ${ }^{b}$ IFSTTAR-COSYS / ESTAS, Lille-Villeneuve d'Ascq, France \\ ${ }^{c}$ University Lille 1, Lille-Villeneuve d'Ascq, France \\ ${ }^{d}$ SNCF Réseau, Paris, France
}

\begin{abstract}
Level Crossing (LX) safety is one of the most critical issues for railways. Collisions between trains and motorized vehicles contribute most to LX accidents, while the risky behavior of motorists is the primary cause of such accidents. Therefore, motorist behavior at LXs is a safety concern that requires special attention care. The present study is a tentative to acquire a better understanding of risky motorist behavior at LXs. Namely, risk analysis of motorist behavior is performed based on field observation conducted at 11 automatic LXs (10 equipped with two half barriers (SAL2) and 1 equipped with four half barriers (SAL4)). We particularly focus on motorist behavior during the LX closure cycle when the barriers are closed down completely. Based on recorded measurements, the zigzag violation rate is analyzed with regard to the prolonged LX closure duration and LX location (railway station nearby or not), respectively. Then, some other features characterizing risky behavior are determined, such as troop phenomenon, etc. Besides, since our aim is to analyze motorist behavior at SAL2 LXs, one SAL4 LX was considered in our experiments to examine the distinction of motorist responses to SAL2 and SAL4 protection systems, so as to compare the efficiency of SAL2 and SAL4 LXs in terms of safety. In summary, the findings of our analysis offer a novel insight for interpreting significant aspects underlying motorist decision-making during the LX closure cycle and facilitate identifying technical solutions to improve LX safety.
\end{abstract}

Keywords: Railway safety; Level crossing safety; Train-vehicle collisions; Zigzag violations; Statistical analysis;

\section{Context and related works}

Accidents at railway level crossings (LXs), particularly collisions between trains and motorized vehicles, often give rise to serious material and human damage and seriously hamper railway safety reputation, although the majority of accidents are caused by motorist violations. Therefore, LX safety is one of the most critical issues for railways, which needs to be tackled urgently (Ghazel, 2009; Liu et al., 2016; Mekki et al., 2012). In 2012, there were more than 118,000 LXs in the 28 countries of the European Union (E.U.), and 5 LXs per 10 line-km on average in the E.U. (ERA, 2014). LX accidents account for about $30 \%$ of the total number of railway accidents in Europe and cause more than 300 deaths every year (Liu et al., 2016). In some European countries, LX accidents account for up to $50 \%$ of railway accidents (Evans, 2011a; Ghazel and El-Koursi, 2014). The railway network in France shows more than 18,000 LXs for 30,000 km of railway lines and around 13,000 LXs show heavy road and railway traffic (SNCF Réseau, 2011). More than 16 million vehicles on average cross LXs every day and 450,000 LX closure cycles take place accordingly. Once a motorized vehicle exists at the LX intersection zone during the LX closure cycle when a train is approaching, the train cannot be stopped to avoid colliding with the vehicle, since trains can be very heavy, weighing up to 1,500 tonnes and a train running at $90 \mathrm{~km} / \mathrm{h}$ generally needs $800 \mathrm{~m}$ to stop (Ghazel, 2017). In 2013, $€ 32$ million was spent by the State, SNCF (the French national railway operator) and local authorities, to improve safety at LXs, and about $€ 36$ million was invested in 2014. Despite numerous measures taken to improve LX safety, SNCF Réseau counted 111 collisions at LXs leading to 31 deaths and 15 severe injuries in 2016 (Plesse, 2017). This number was half the total number of collisions per year at LXs a decade ago, but still too large. In order to efficiently 
improve LX safety, it is crucial to carry out a thorough analysis to understand motorist behavior during the closure cycles of LXs. This draws the background and motivation of the current study.

In the existing literature, a number of works have dealt with LX safety. In early studies, motorist behavior with respect to the warning time of LX control was studied by Richards and Heathington (1990). Their study indicated that an increase in warning time was directly linked with an increase in risky motorist behavior. Ward and Wilde (1995a) reported a field study regarding a signage warning system for passive LXs with restricted lateral visibility. The proposed signage incorporates a stop sign and an advance warning to announce the restricted visibility. In this study, the vehicles were tracked through a series of seven sonar units placed along the roadside at incremental distances from the LX. It was reported that the approach speed of the vehicles approaching the LX did decrease after the installation of the signs. Abraham et al. (1998) have studied motorist behavior at 37 LXs in Michigan and reported various driver characteristics and vehicle characteristics to be important safety factors. This study showed that the motorists approaching a multi-track LX from a multi-lane approach commit more violations. Cooper et al. (2007) presented the research on selecting countermeasure improvements for LXs in California and suggested the use of two-long-arm gates or standard two-half gates with an additional median separator for LX safety improvement according to the calculated benefit/cost ratio. Khattak (2009) has made a comparison of motorist behavior at LXs in two cities of Nebraska. This research has showed that motorists' unsafe behavior at LXs is location-dependent, but the magnitude of reduction in unsafe motorist actions as a result of the installation of a separator along the road center at different LXs is more or less similar.

In the recent literature, few works focus on the analysis of motorist behavior with regard to the separate phases of the automated LX closure cycle. Some available studies adopted qualitative approaches for understanding motorist behavior during the entire cycle of LX control, including when the LX is open to road traffic (e.g. Shappel and Wiegmann, 2000; San Kim and Yoon, 2013). For example, a systems analysis framework (Read et al., 2016; Wilson, 2014) and a psychological schema theory (Stanton and Walker, 2011; Salmon et al., 2013) have been used to analyze the contributory factors underlying LX accidents. Salmon et al. (2016) adopted the Cognitive Work Analysis (CWA), which is a systems approach with theoretical underpinnings in system theory, to achieve comprehensive understanding of different functions, decisions, strategies and tasks relevant to various LX stakeholders (road user, rail user and authorities). This study suggested further mechanisms for collecting and analyzing actual field data, which are crucial for allowing stakeholders to identify the key design requirements to improve safety at LXs. Some works (involving qualitative and quantitative means) employ surveys (Wigglesworth, 2001), interviews (Read et al., 2016), focus group methods (Stefanova et al., 2015) or driving simulators (Larue et al., 2015), rather than collecting real field data. For example, Lenné et al. (2011) examined the effect of installing active controls, flashing lights and traffic signals on vehicle driver behavior. This study was achieved through the driving simulator. Rudin-Brown et al. (2012) carried out a driving simulator study that compared the efficacy and drivers' subjective perception of two active LX traffic control devices: flashing lights with boom barriers and standard traffic lights. A study launched by Young et al. (2015) examined where drivers direct their attention on approach to urban LXs located in busy shopping strip areas in Melbourne, and whether this differs between novice and experienced drivers. Instrumented vehicles, driver Verbal Protocols and post-drive Critical Decision interviews are utilized in this study. Tey et al. (2011) conducted an experiment to measure vehicle driver response to LXs equipped with stop signs (passive), flashing lights and half barriers with flashing lights (active), respectively. In this study, both a field survey and a driving simulator have been utilized. However, we believe that the reaction of vehicle drivers in simulation context may differ from that in reality, due to the different levels of feeling of danger. Davey et al. (2008) performed a study that aims to explore the contributing factors toward collisions at LXs from the perception of both heavy vehicle drivers and train drivers. In particular, a survey was conducted and samples of train drivers and heavy vehicle drivers were recruited as a series of focus groups. In this study, the contributing factors to heavy vehicle accidents at LXs such as the heavy vehicle size, the carriage length, the line of sight and the impeded acceleration were assessed using qualitative investigation.

Although research on human factors related to LX safety has been an area of great concern over the past decades (Wilson and Norris, 2005; Wilson, 2014), the causes of collisions that occur at LXs remain insufficiently understood. In general, the causes of such collisions fall into two broad classes, which are unintentional error and intentional violation. As for the unintentional errors, vehicle drivers may, for instance, fail to observe the warnings or fail to determine the braking distance appropriately. However, as for the intentional violations, vehicle drivers observe the warnings and fully understand their meaning, but intentionally commit transgressions on their own judgment (Lenné et al., 2011). In the present study, we carry out experiments that aim to quantitatively and finely analyze intentional 
zigzag violations of motorists when LX barriers are closed. These experiments have been conducted at 11 automated LXs in France, among which there are 10 LXs equipped with two half barriers and 1 equipped with four half barriers.

The originality of the present study is three-fold: 1) based on some experimental devices, we are able to record the dynamics and category of each individual vehicle crossing the LXs during the observation period. Moreover, a synchronization with the LX local control module allows for determining the LX control phase (cf. section 2.1) corresponding to each individual crossing vehicle. 2) Based on the field data collected, motorist behavior during "Ph4 Barriers Down" of the closure cycle (cf. section 2.1) is specifically considered. This gives a novel insight compared with existing studies which analyze motorist behavior during a whole mixed LX control cycle. 3) Thorough behavioral analysis has been carried out on i) the zigzag violation rate during $\mathrm{Ph} 4$ with regard to the prolonged $\mathrm{LX}$ closure duration and LX location (railway station nearby or not), respectively, ii) some other features characterizing risky behavior, such as troop phenomenon, etc. and iii) the distinction of motorist responses to SAL2 and SAL4 LXs with regard to various phases of the closure cycle, which are rarely presented in existing works.

The current paper is structured as follows: the context of the conducted study and a review of existing related works on LX safety analysis are given in section 1 . Section 2 is dedicated to the research objective, the experimental process and data collection. Analysis of zigzag violation scenarios is elaborated in section 3. Namely, the violation rate, waiting queue and troop crossing phenomenon are analyzed with regard to the closure cycle duration, the LX location and road traffic density. The comparison of motorist responses to SAL2 and SAL4 LXs is performed in section 4. A detailed discussion about some influential factors and practical countermeasures for improving LX safety is carried out in section 5. Finally, section 6 provides some concluding remarks and outlines a number of issues for future work.

\section{Method}

\subsection{Experimental objective}

There are four main LX types in France (SNCF, 2015), as shown in Fig. 1:

a) SAL4: Automated LXs equipped with four half barriers and flashing lights;

b) SAL2: Automated LXs equipped with two half barriers and flashing lights;

c) SAL0: Automated LXs equipped with flashing lights but without barriers;

d) Crossbuck LXs, without automatic signaling.

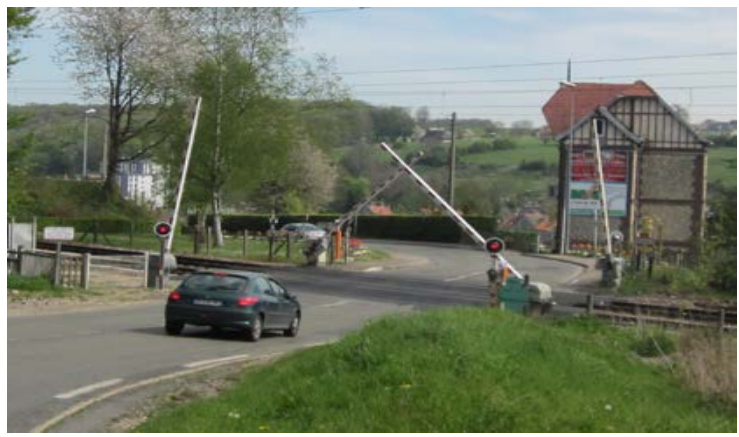

(a) SAL4

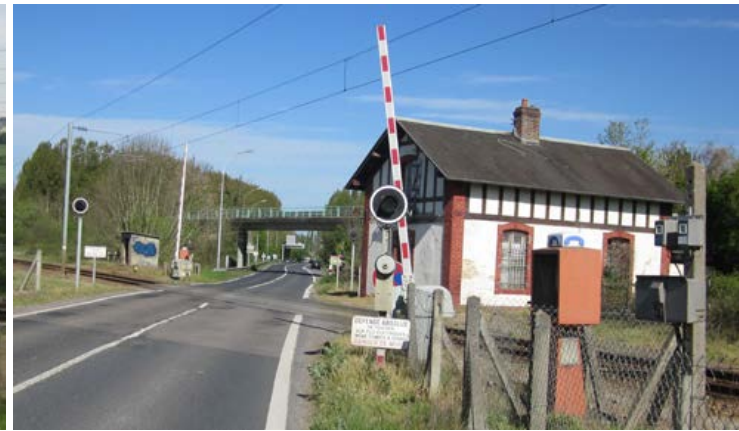

(b) SAL2 


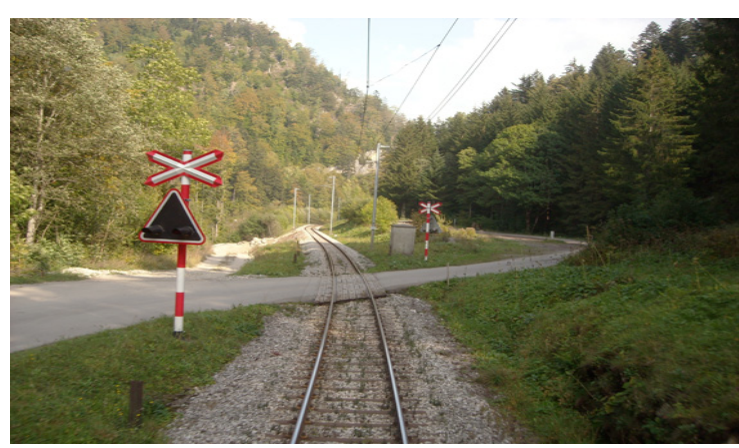

(c) SAL0

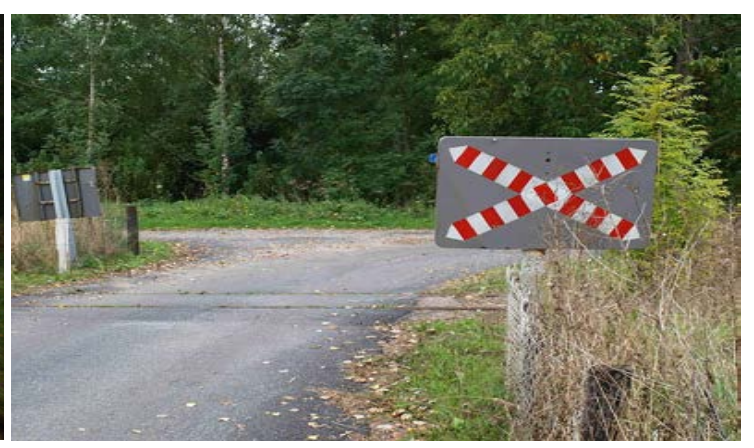

(d) Crossbuck LX

Fig. 1. Four types of LXs in France.

As shown in Table 1, SAL2 (more than 10,000) is the most widely used type of LX in France according to the LX data recorded by SNCF. Moreover, more than 4,000 accidents at SAL2 contributed most to the total number of accidents at LXs from 1974 to 2014. According to the previous statistical analysis, motorized vehicle is the main transport mode causing accidents at LXs (Liang et al., 2017). Considering the train/motorized vehicle (train-MV)

Table 1. Accidents at different types of LXs in France from 1974 to 2014.

\begin{tabular}{lll}
\hline Type of LX & Number & \# Accident \\
\hline SAL4 & $>600$ & $>600$ \\
SAL2 & $>10,000$ & $>4,200$ \\
SAL0 & $>60$ & $>50$ \\
Crossbuck LX & $>3,500$ & $>700$ \\
\hline
\end{tabular}

collisions, SAL2 LXs also have the most accidents from 1978 to 2013 according to the statistics shown in Fig. 2. In fact, the goal of SNCF is to perform analysis that paves the way toward significantly improving LX safety as a whole. Hence, being given the number of SAL2 LXs, dealing with this LX category consists a priority issue for SNCF. In addition, according to the SNCF statistics, the accidents at SAL2 LXs can be considered as the most representative for LX accidents in general. For all these reasons, we will focus on the analysis of train-MV collisions occurring at SAL2 LXs. It should be noted that suicide scenarios are not in the scope of our global study.

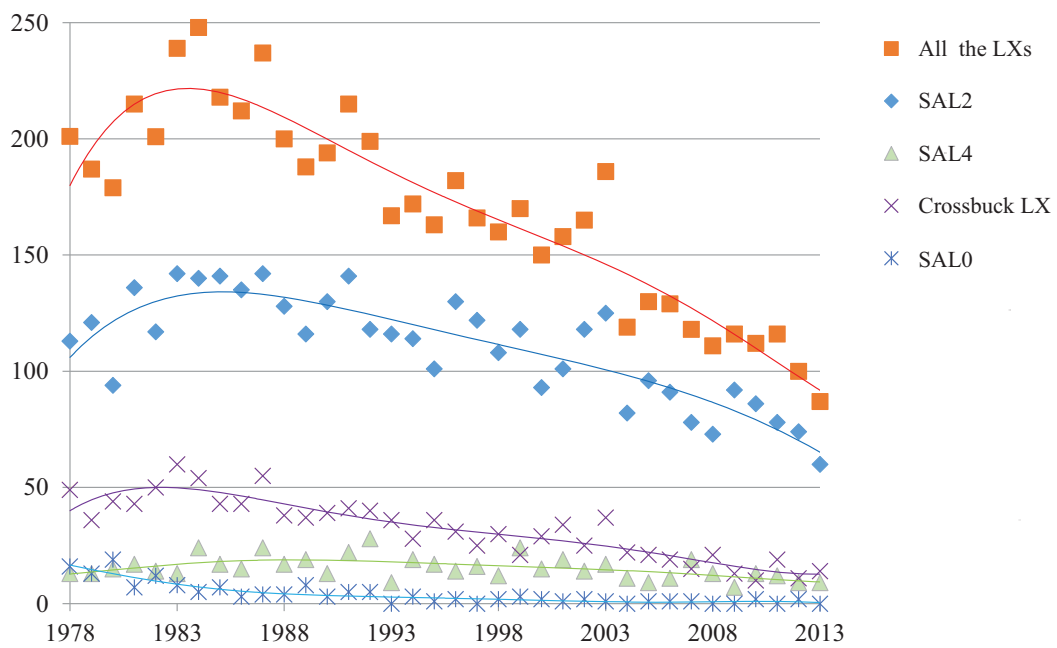

Fig. 2. The number of train-MV collisions at different types of LX in France from 1978 to 2013. 
The control cycle of SAL2 LXs (as well as SAL4 LXs) consists of 5 phases:

- Ph0 "Unflash and Barriers Coming Up": corresponds to the phase launched just after the crossing train leaves the intersection zone. In this phase, the warning lights stop flashing, the sirens stop blaring and the barriers are rising.

- $\mathrm{Ph} 1$ "Barriers Up": corresponds to the phase when the LX is open for road traffic as no train is approaching. In this phase, the barriers are fully opened.

- $\mathrm{Ph} 2$ "Red Flash and Siren": corresponds to the first phase of the closure cycle right after an approaching train is detected. In this phase, the warning lights flash and sirens whistle, whereas the barriers are kept raised.

- Ph3 "Barriers Coming Down": is the second phase of the closure cycle. In this phase, the barriers are falling.

- $\mathrm{Ph} 4$ "Barriers Down": is the third phase of the closure cycle. In this phase, the barriers are fully lowered and the lights keep flashing.

When analyzing LX accident scenarios, the scenario consisting in road vehicles bypassing the half barriers to cross the SAL2 LX when it is closed for the road traffic (zigzag) has been identified as a major scenario causing train-MV collisions (Ghazel, 2017). Therefore, the analysis of motorist behavior at SAL2 LXs during Ph4 "Barriers Down" of the LX closure cycle is important to scrutinize the major risky scenario causing LX train-MV accidents and allows for a detailed assessment of various aspects related to zigzag violations of motorists. This is our consideration that the present study is dedicated to discussing motorist behavior at SAL2 LXs during Ph4.

\subsection{Selection of case study LXs}

Ten SAL2 LXs, named according to their respective locations, i.e., LX 2 Toulouse, LX 4 Marnes-la-Coquette, LX 21 Pont-Sainte-Maxence, LX 55 Ectot lès Baons, LX 58 Yvetot, LX 69 Gonfreville, LX 71 Remaucourt, LX 82 Neufchâteau, LX 136 Choloy, LX 356 Caussade and one SAL4 LX (LX 425 Chaniers), were selected for our field measurement campaign. Since our aim is to analyze motorist behavior at SAL2 LXs, the SAL4 LX is considered in our experiments for the purpose of comparing motorist responses to SAL2 and SAL4 LXs. As shown in Fig. 3, 11 LXs are indicated on the French map. The red circular marks represent the accurate locations of the selected LXs and the railway stations in the vicinity of these LXs are also indicated by black triangle marks. 


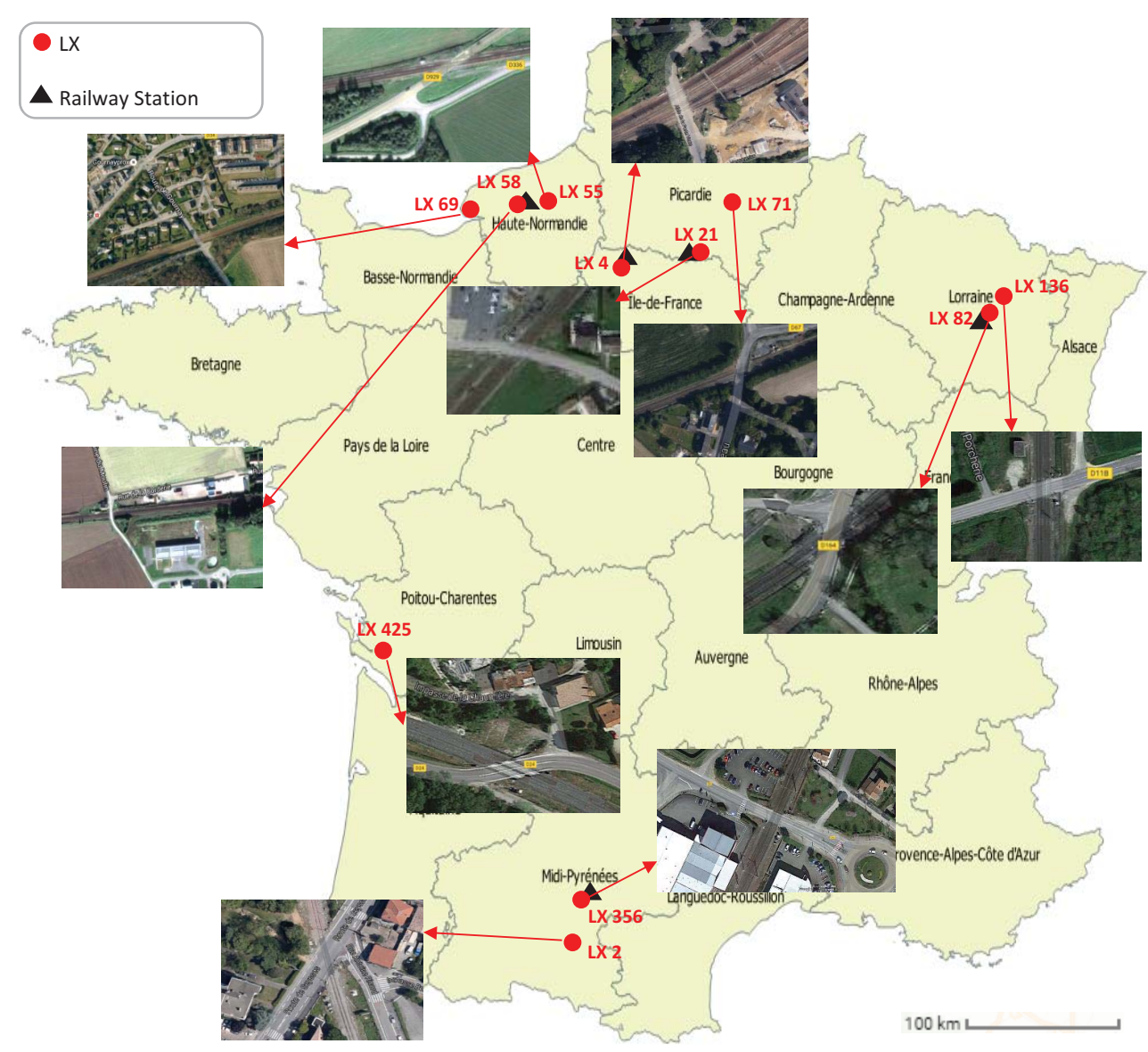

Fig. 3. Geographic information about 11 LXs.

The 11 LXs were selected based on various features (e.g., environment, infrastructure, equipment, railway line and road traffic involved, etc.) as well as their accident/incident statistics (cf. Table 2). The LX selection process ensures that the selected 11 LXs are representative of the range across France when considering various LX features that we aim to analyze. Indeed, the selection of the LXs sample was based on both quantitative and qualitative assessments. Namely, we have analyzed the historical LX accident/incident data from 1974 to 2014, which were collected by SNCF and recorded in dedicated databases. Moreover railway and road traffic densities have been considered as well as the vicinity of the LXs. As shown in Table 2, when considering the number of accidents, LX 2 and LX 4 take the first place among the $11 \mathrm{LXs}$ considered. While considering the sum of accidents and near misses, LX 55 takes the first place. 
Table 2. Collisions/near misses and road/rail traffic volumes at the LXs from 1974 to 2014.

\begin{tabular}{llllll}
\hline LX & Type & \# Accidents & \# Near misses & \# Average daily road traffic & \# Average daily train traffic \\
\hline LX 2 & SAL2 & 5 & 7 & 4250 & 43 \\
LX 4 & SAL2 & 5 & 6 & 1184 & 124 \\
LX 21 & SAL2 & 0 & 8 & 570 & 77 \\
LX 55 & SAL2 & 3 & 114 & 21491 & 70 \\
LX 58 & SAL2 & 0 & 5 & 13938 & 89 \\
LX 69 & SAL2 & 0 & 1 & 10946 & 91 \\
LX 71 & SAL2 & 0 & 5 & 985 & 93 \\
LX 82 & SAL2 & 4 & 40 & 2500 & 94 \\
LX 136 & SAL2 & 3 & 8 & 3525 & 94 \\
LX 356 & SAL2 & 2 & 8 & 2892 & 59 \\
LX 425 & SAL4 & 1 & 4 & 5425 & 37 \\
\hline
\end{tabular}

\subsection{Road traffic measurement}

This field observation campaign (over a period of 9 weeks) has been conducted by SNCF Réseau. The sensing equipment installed at each LX consists of two separate tubes one meter apart. As shown in Fig. 4, taking LX 58 for example, these two tubes are placed perpendicularly to road traffic direction on the ground in front of the stop line, just before the LX barriers. They are connected to a counter that is a digital recording module, which, in turn, is linked to the light flashing signal to ensure synchronization with the signal cycle. The synchronization between the installed counting module and the LX control module is achieved by means of an optical sensing device installed in front of the LX flashing lights in both directions. Indeed, for safety reasons, SNCF Réseau requires that the counting module cannot interfere with the LX control module. In other words, one cannot get information about the LX status by connecting directly to the LX control module. In fact, French railways rely on a safety principle called GAMÉ (Globally at Least Equivalent) which ensures that each modification or replacement of any safety critical module must not degrade the global safety level of the system considered. Thanks to the installation set, the timestamp, vehicle direction, vehicle speed and phase, are recorded for each crossing vehicle individually.

The detailed traffic data collected through our installation are recorded in a specific database. As shown in Fig. 5a, a tool, called "MTExec", is provided to visualize and handle the recorded data. Fig. 5b shows an example of road traffic data that are presented in the MTExec tool. As can be noted, the timestamp, vehicle direction, vehicle speed, vehicle type and phase information are recorded distinctly. Based on these records, the vehicle dynamics can be fully characterized.

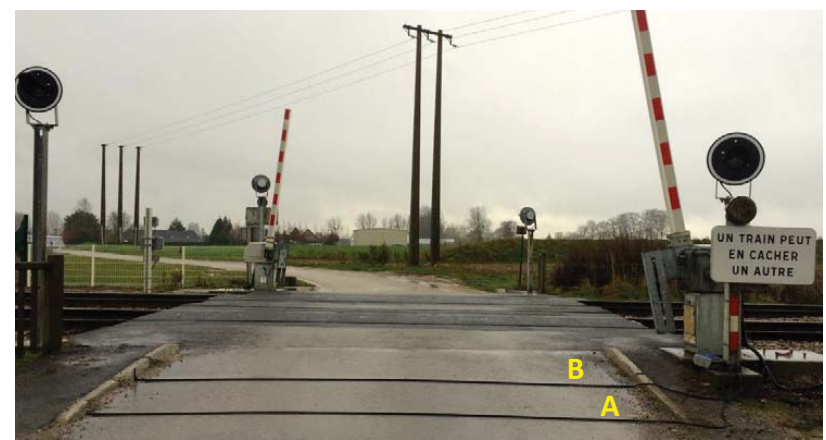

Fig. 4. Labeled photographs of environment and devices at LX 58. 


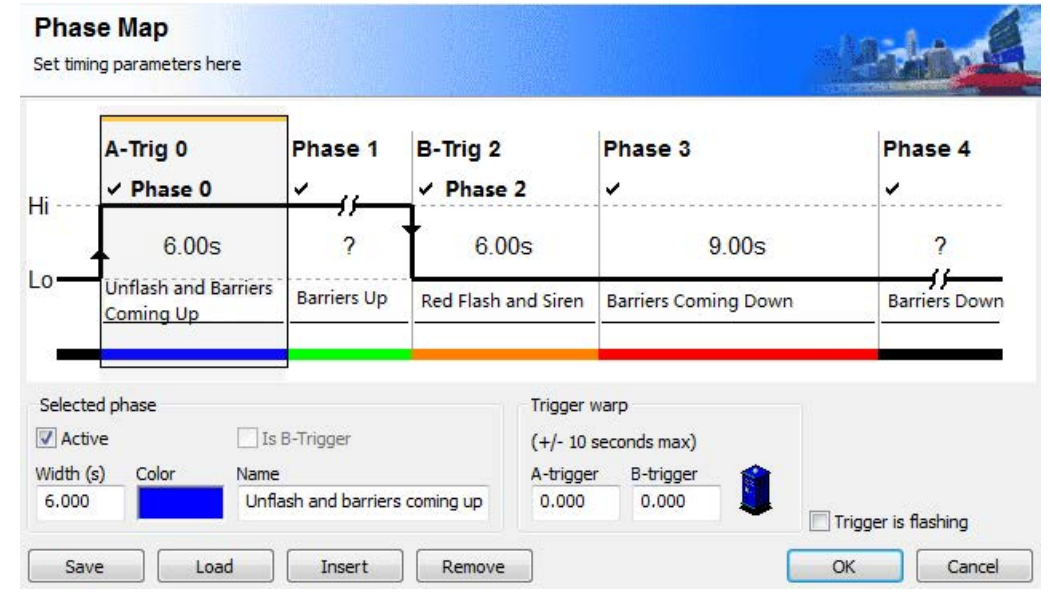

(a) The tool "MTExec" provided by MetroCount.

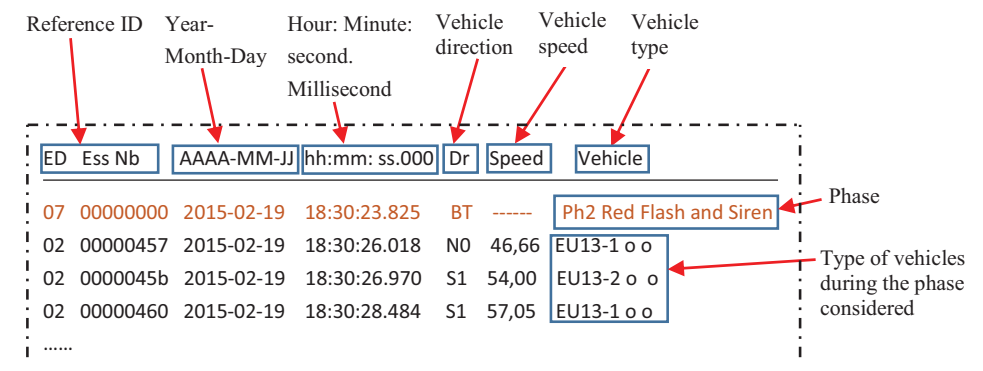

(b) Example of road traffic data recorded.

Fig. 5. The tool "MTExec" and an example of road traffic data recorded in the MTExec tool.

It should be noted that, in terms of ethics approval, the data collected during the experiments do not hold any personal or private aspects. Only the agreement to install the measurement devices is needed.

\section{Behavioral analysis}

The violation rate related to prolonged $\mathrm{Ph} 4$ duration, zigzag occurrence related to $\mathrm{LX}$ location and dispersive $\mathrm{Ph} 4$ duration and finally, waiting queue and troop crossing phenomenon related to road traffic density and zigzag moment are discussed thoroughly. In fact, during the period of observation, the total crossings recorded at the 10 SAL2 LXs were 461596, where there were 5678 crossings happened during the closure cycle and 116 zigzags happened during $\mathrm{Ph} 4$. Namely, the general average violation rate is $1.230 \%$ and the general average zigzag rate is $0.025 \%$.

\subsection{The impact of prolonged Ph4 duration}

The duration of $\mathrm{Ph} 4$ shows an important discrepancy from one closure cycle to another according to the actual speed of the train involved. In fact, the sensors responsible for announcing the train's approach to the local LX control system are implemented in such a way as to ensure that the LX closure is triggered to ensure a minimum given delay prior to the train arrival at the intersection zone. Therefore, the location of the announcement sensors which detect the train arrival is set according to the speed limit of the track section. Thus, according to railway operation standards in France, the shortest time for train arriving at SAL2 intersection zone is $25 \mathrm{~s}$ following the starting of the closure cycle. Nevertheless, since different train categories, such as freight and passenger trains (with different speeds) may pass on the section where the LX is located, such a control scheme leads to inevitable long closure durations in the case of slow trains. Train-MV collisions are most likely to occur when vehicles start to cross the LX $5 \mathrm{~s}$, at the earliest, before 
trains arriving since after this delay they would not have enough time to leave the intersection zone before the train arrives. The durations of $\mathrm{Ph} 2$ "Red Flash and Siren" and $\mathrm{Ph} 3$ "Barriers Coming Down" can be considered as to be constant at each LX. Table 3 shows the duration of $\mathrm{Ph} 2$ and $\mathrm{Ph} 3$ at each LX. One can notice that the average duration of $\mathrm{Ph} 2$ and $\mathrm{Ph} 3$ altogether at these LXs is about $16 \mathrm{~s}$. Therefore, we focus more particularly on the motorist violations after the first $4 \mathrm{~s}$ of $\mathrm{Ph} 4(25 \mathrm{~s}-5 \mathrm{~s}=20 \mathrm{~s}=16 \mathrm{~s}+4 \mathrm{~s}$, where 16=length $(\mathrm{Ph} 2)+$ length $(\mathrm{Ph} 3))$ in the following analysis.

Table 3. Duration of $\mathrm{Ph} 2$ and $\mathrm{Ph} 3$ at each $\mathrm{LX}$.

\begin{tabular}{lll}
\hline LX & Ph2 duration & Ph3 duration \\
\hline LX 2 & 8 & 12 \\
LX 4 & 7 & 8 \\
LX 21 & 7 & 8 \\
LX 55 & 6 & 9 \\
LX 58 & 8 & 7 \\
LX 69 & 7 & 9 \\
LX 71 & 8 & 9 \\
LX 82 & 7 & 8 \\
LX 136 & 9 & 8 \\
LX 356 & 8 & 8 \\
LX 425 & 7 & 9 \\
\hline
\end{tabular}

In $\mathrm{Ph} 4$, violating vehicles skirt the half barriers to cross the LX, which represents a highly risky scenario. If one only considers the number of vehicle violations during $\mathrm{Ph} 4$, there is a possibility that, although the violation volume is high, the entire traffic volume is relatively high as well during the same period. Therefore, it is more appropriate to analyze the violation rate as expressed by Eq. (1).

$$
\text { Violation rate }_{P h 4}=V V_{M} /\left(V D \times D_{M}\right)
$$

where Violation rate $_{P h 4}$ represents the violation rate during $\mathrm{Ph} 4, V V_{M}$ is the number of violating vehicles during a period $D_{M}$ extending from $\mathrm{Ph} 4$ up to the violation moment, $V D$ is the road traffic density during $\mathrm{Ph} 4$. It should be noted that we consider the value of the vehicle density during the one-hour time slot including the $\mathrm{Ph} 4$ considered to estimate the total number of vehicles waiting in front of the LX during $D_{M}$, since this number cannot be determined directly.

Table 4 shows the average road traffic density and the violation rate during the observation period at each LX, ranked according to the average road traffic density in descending order. Besides, the $11 \mathrm{LXs}$ can be divided into 3 groups, i.e., G1, G2 and G3, according to the average road traffic density. The average road traffic density of the LXs in G1, G2 and G3 is more than 0.1 , from 0.01 to 0.1 and less than 0.01 , respectively. We aim to determine the impact of $\mathrm{Ph} 4$ duration on "zigzag" motorist behavior. Generally, one would conjecture that a higher rate of "zigzag" violations would appear as the duration of $\mathrm{Ph} 4$ is extended. A thorough analysis is carried out to validate whether this general speculation, commonly assumed, is correct. Therefore, we adopt the average violation rate at those LXs having zigzags (cf. Table 4) to determine the overall trend of violation rate as time advances. The average violation rate is the average value of the samples of exact violation rate during each time interval involved, which can lessen the dispersion of exact violation rate values and make the trend clearer. In addition, as the number of zigzags recorded at night is very limited, we only consider those committed in the daytime (from 6:00 $\mathrm{h}$ to 21:00 h) exclusively.

Hence, by reporting the average ratio of the number of recorded zigzags during $D_{M}$, to the estimated number of vehicles during this period, and the duration of $D_{M}$, we determine the average violation rate distributed according to the time interval starting from $\mathrm{Ph} 4$ up to the violation moment. As shown in Fig. 6, the global trend of the average violation rate is drawn as the duration of the waiting time interval extends. The average violation rate is the average value of the samples of exact violation rate during each time interval involved, which can lessen the dispersion of exact violation rate values and make the trend clearer. This curve attests that the violation rate during $\mathrm{Ph} 4$ decreases as $\mathrm{Ph} 4$ duration is prolonged (the longer the waiting time interval starting from $\mathrm{Ph} 4$ up to the violation moment, the 
Table 4. Information about average road traffic density and violation rate during the observation period at each LX.

\begin{tabular}{lllll}
\hline Group & LX & Average road traffic density $(/ \mathrm{s})$ & Violation rate & Near to railway station \\
\hline G1 & LX 55 & 0.247 & 0.134 & No \\
G1 & LX 58 & 0.167 & 1.957 & Yes \\
G1 & LX 69 & 0.126 & 1.060 & No \\
G2 & LX 356 & 0.062 & 0.414 & Yes \\
G2 & LX 2 & 0.054 & 0.995 & No \\
G2 & LX 425 & 0.053 & - & No \\
G2 & LX 82 & 0.037 & - & Yes \\
G2 & LX 136 & 0.018 & - & No \\
G2 & LX 71 & 0.017 & - & No \\
G3 & LX 4 & 0.009 & 0.259 & Yes \\
G3 & LX 21 & 0.005 & 0.715 & Yes \\
\hline \multicolumn{7}{l}{ “-” means that no zigzags are observed at these LXs during the experiment period. }
\end{tabular}
longer the Ph4 duration). This outcome demonstrates that the general speculation $\mathrm{m}$
of "zigzag" violations would appear as the duration of $\mathrm{Ph} 4$ is extended is not valid.

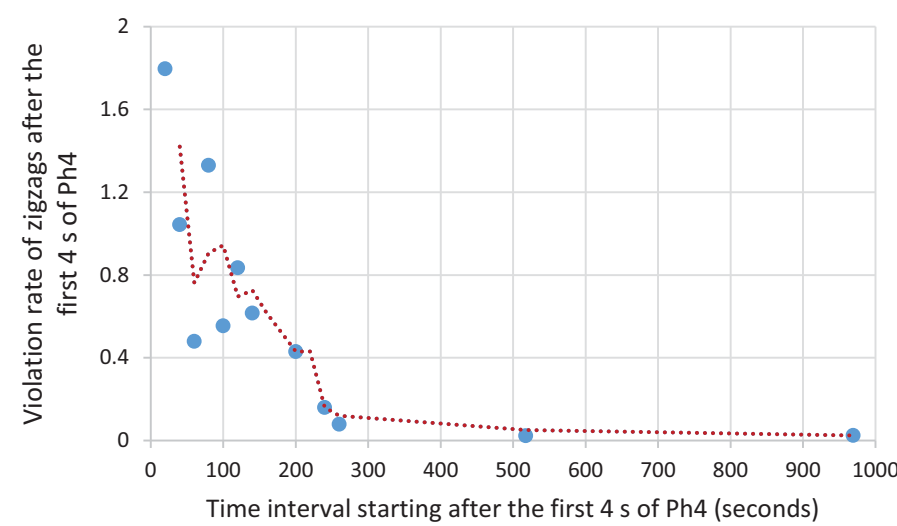

Fig. 6. The average violation rate of zigzags during $\mathrm{Ph} 4$ as $\mathrm{Ph} 4$ duration prolonged.

\subsection{The impact of LX location (near to railway station or not)}

In order to further analyze the factors influencing zigzag occurrence, we scrutinize the $\mathrm{Ph} 4$ duration at each $\mathrm{LX}$ during the observation period. As shown in Fig. 7, $\mathrm{Ph} 4$ duration distribution during the observation period is drawn with regard to 20 equal classified slots.

As for the LXs in G1 (cf. Fig. 7a), the Ph4 duration distribution at LX 58 is quite dispersive. On the contrary, the Ph4 duration distributions at LX 55 and LX 69 are more centralized. As for the LXs in G2 and G3 (cf. Fig. 7b and Fig. 7c), the Ph4 duration distributions at LX 356 and LX 21 are relatively dispersive, compared with other LXs in these two groups, respectively. Referring to Table 4, these LXs with dispersive $\mathrm{Ph} 4$ durations are quite close to railway stations. Thus, some trains go through slowly or just stop above the LX announcement sensors for shortly stopping in railway stations nearby. Indeed, in some cases, the sensors are installed around or in the railway stations. This fact explains the dispersive $\mathrm{Ph} 4$ duration distribution. 


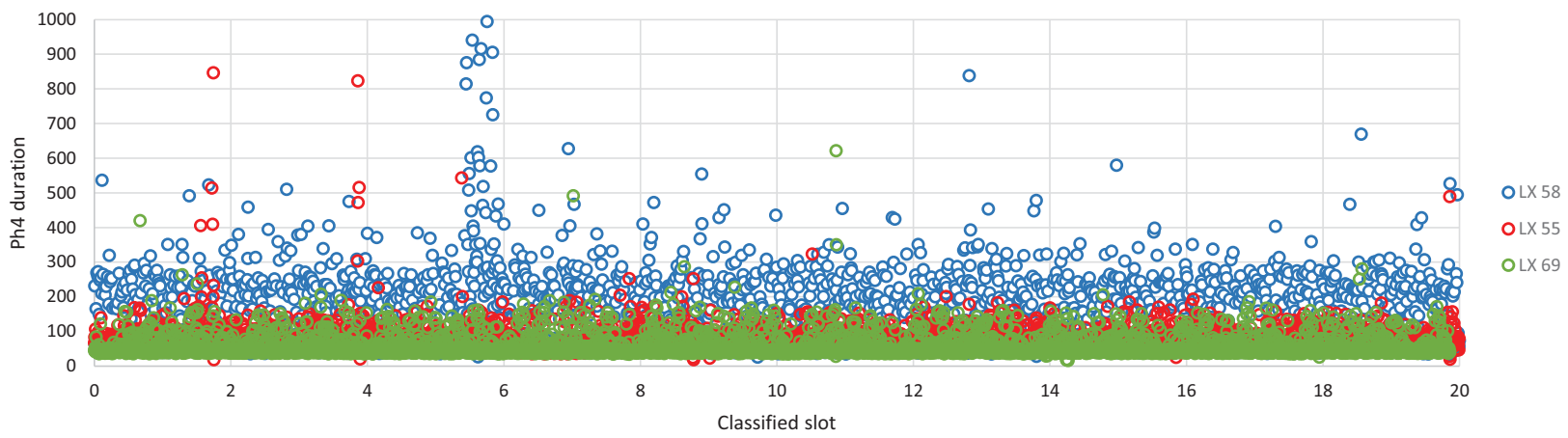

(a) $\mathrm{Ph} 4$ duration distribution of LXs in G1.

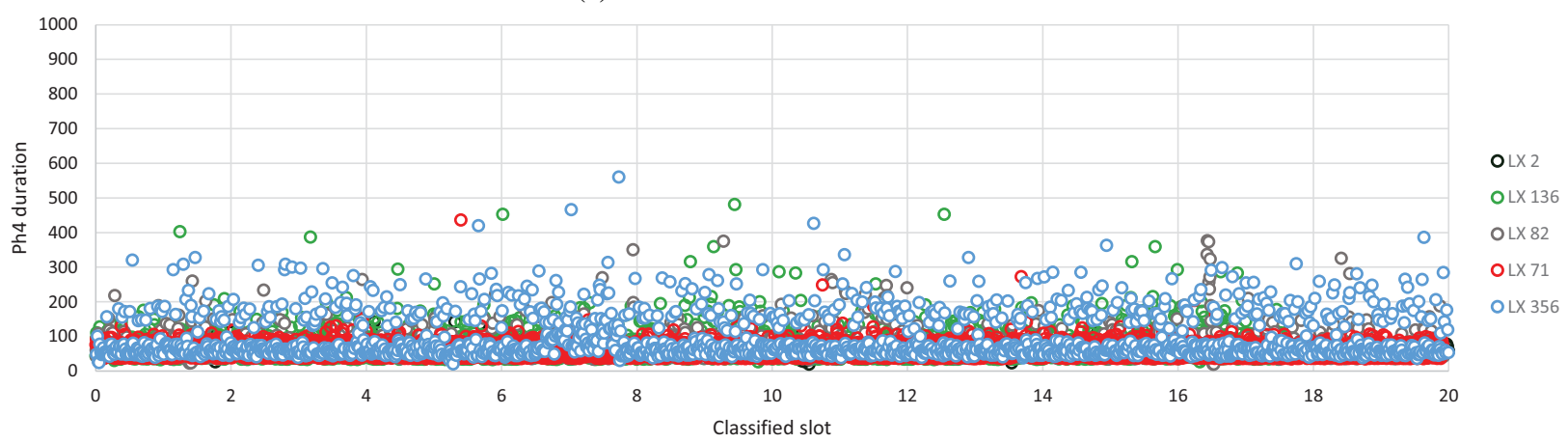

(b) Ph4 duration distribution of LXs in G2.

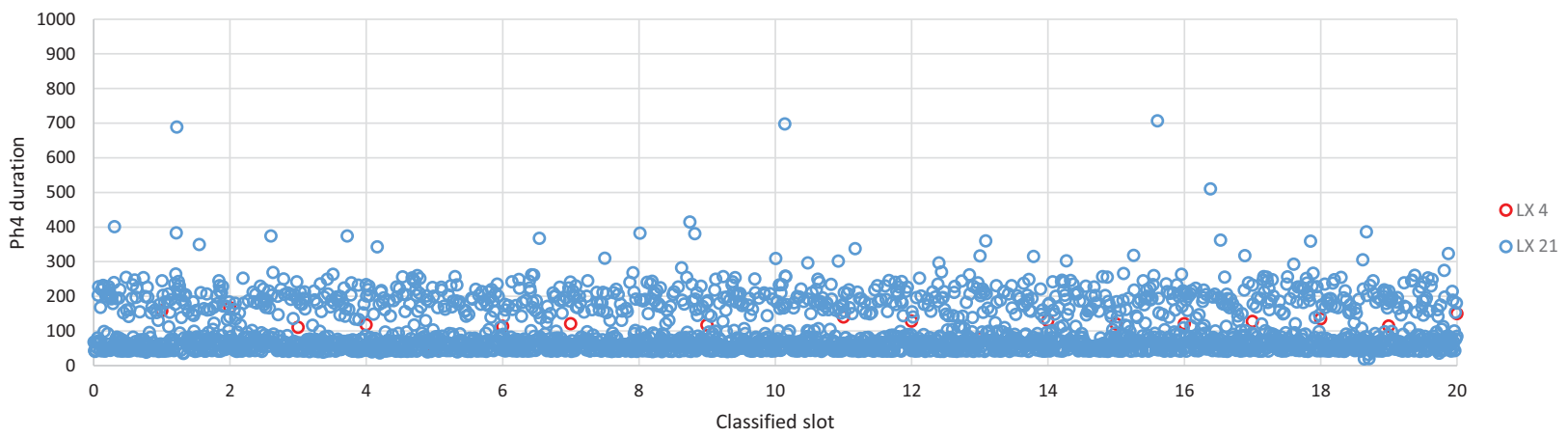

(c) Ph4 duration distribution of LXs in G3.

Fig. 7. Ph4 duration distribution with regard to classified slots.

These dispersion characteristics can be indicated more clearly through Fig. 8 which shows the cumulative distribution of Ph4 duration at the considered LXs. As shown in Fig. 8a, it is worth noticing that, for the LXs in G1, the cumulative distribution curves of $\mathrm{Ph} 4$ duration at LX 55 and LX 69 climb dramatically during the first $100 \mathrm{~s}$ of $\mathrm{Ph} 4$, then reach 1 after $200 \mathrm{~s}$. That means Ph4 durations at LX 55 and LX 69 are quite centralized within the first $100 \mathrm{~s}$ of $\mathrm{Ph} 4$. It is because, to a large extent, no railway stations are near to these LXs. However, the cumulative distribution curve of Ph4 duration at LX 58 shows inflection points at $100 \mathrm{~s}$ and $280 \mathrm{~s}$, which indicates that Ph4 durations at LX 58 are relatively dispersive (from $100 \mathrm{~s}$ to $280 \mathrm{~s}$ ). This is due to the fact that LX 58 is close to a railway station. More importantly, the violation rate at LX 58 is also the highest compared with that at LX 55 and LX 69.

As for the LXs in G2 and G3 (cf. Fig. 8b), LX 21 has the most dispersive Ph4 duration followed by LX 356 and LX 4 in sequence, according to their cumulative distribution curves of $\mathrm{Ph} 4$ duration. One can still note that these 3 LXs are all close to railway stations. Moreover, LX 21 has the highest violation rate among these 3 LXs followed by LX 356 and LX 4 in sequence, accordingly. There is only one exception that LX 2 has a high violation rate but 


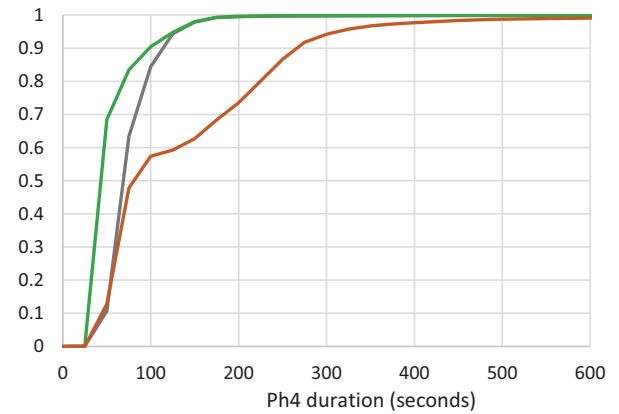

(a) The cumulative distribution of Ph4 duration at LXs in G1.

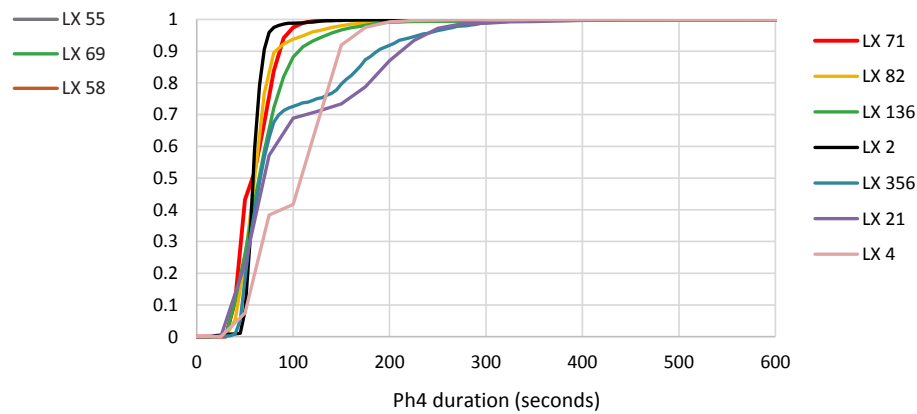

(b) The cumulative distribution of Ph4 duration at LXs in G2 and G3.

Fig. 8. The cumulative distribution of $\mathrm{Ph} 4$ duration.

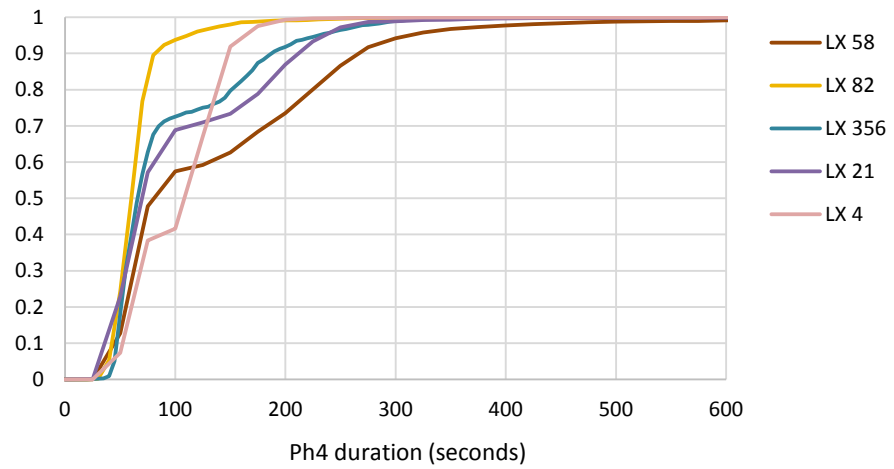

Fig. 9. The cumulative distribution of Ph4 duration at those LXs close to railway stations.

does not have dispersive $\mathrm{Ph} 4$ durations (while no railway station nearby). The surrounding of LX 2 will be further investigated in future works to explore other potential reasons for the high violation rate at this LX.

In order to thoroughly analyze the violation rate at each LX close to railway station, we extract the cumulative distribution (CD) curves of $\mathrm{Ph} 4$ duration at those LXs in Fig. 9. Moreover, the corresponding slope rates of CD between $0 \mathrm{~s}$ and $200 \mathrm{~s}$ of $\mathrm{Ph} 4$ are shown in table 5, which can reflect the dispersion of $\mathrm{Ph} 4$ duration at the five LXs. It is worth noticing that LX 58 has the most dispersive Ph4 duration (Slope rate $=0.0037$ ) among these 5 LXs and LX 21 (Slope rate $=0.0044)$ takes the second place followed by LX 356 (Slope rate = 0.0046), LX 4 (Slope rate = 0.0050 ) and LX 82 (Slope rate $=0.0050$ ) in sequence. On the other hand, as shown in table 5, the violation rates of the 4 LXs (except LX 82) follow the same order, that is LX 58 has the highest violation rate and then LX 21 takes the second place followed by LX 356 and LX 4 in sequence. There are no zigzags or dispersive $\mathrm{Ph} 4$ duration found at LX 82. After checking the railway infrastructure characteristics of LX 82, we have noted that the distance between LX 82 and the railway station is about $1.3 \mathrm{~km}$, however, the distance between the LX announcement sensor and the $\mathrm{LX}$ is only around $700 \mathrm{~m}$. Therefore, as for the LX announcement sensor on the odd track, it has a distance of about 2 $\mathrm{km}$ from the railway station; as for the LX announcement sensor on the even track, it still has a distance of about 600 $\mathrm{m}$ from the railway station. The railway speed limit of the track section including LX $82 \mathrm{is} 150 \mathrm{~km} / \mathrm{h}$ and the railway station also has a certain length $(250-500 \mathrm{~m})$. Namely, trains would not stop above the LX announcement sensors or slow down when they pass the LX announcement sensors on both opposite directions. That is why the railway station nearby does not cause dispersive $\mathrm{Ph} 4$ durations at LX 82. In summary, we can infer that motorists are more likely to commit zigzag violations at the LXs located close to railway stations, i.e., with dispersive $\mathrm{Ph} 4$ durations. Besides, the more dispersive the $\mathrm{Ph} 4$ durations, the higher the violation rate of zigzags. 
Table 5. The slope rates of CD between $0 \mathrm{~s}$ and $200 \mathrm{~s}$ of $\mathrm{Ph} 4$ at those LXs close to railway stations.

\begin{tabular}{llllll}
\hline Group & LX & CD_200 s & Slope rate & Violation rate & Near to railway station \\
\hline G1 & LX 58 & 0.736 & 0.0037 & 1.957 & Yes \\
G3 & LX 21 & 0.870 & 0.0044 & 0.715 & Yes \\
G2 & LX 356 & 0.918 & 0.0046 & 0.414 & Yes \\
G3 & LX 4 & 0.990 & 0.0050 & 0.259 & Yes \\
G2 & LX 82 & 0.991 & 0.0050 & - & Yes \\
\hline \multicolumn{7}{l}{ “-” means that no zigzags are observed at the LX during the experiment period. } \\
\hline
\end{tabular}

\subsection{The impact of road traffic density}

Waiting queues of vehicles in front of LXs can foster troop crossing phenomenon that represents a high-risk scenario. Logically, a waiting queue would be most likely to form since the beginning of $\mathrm{Ph} 3$ "Barriers Coming Down"2. When vehicles arrive at an LX after a certain time since the beginning of $\mathrm{Ph} 4$, there are potentially some vehicles that have arrived earlier at the LX, which are waiting in front of the barriers. After a long time of waiting for the LX open cycle, some motorists may potentially lose their patience. Once the first vehicle in front of the LX commits zigzag crossing, the subsequent vehicles attempt to follow it closely. This scenario is called "troop crossing phenomenon".

We suppose that road traffic density has an impact on the occurrence of waiting queue and troop crossing. Therefore, we chose LX 55, LX 69, LX 2, LX 4 and LX 21 which showed relatively more zigzag occurrences compared with the other LXs.

The length of a waiting queue is reflected by the number of waiting vehicles accumulated from the beginning of $\mathrm{Ph} 3$ up to the time moment of the zigzag occurring, which is expressed by Eq. (2).

$$
W Q=V D \times M
$$

where $W Q$ represents the length of waiting queue when the zigzag occurred; $V D$ is the road traffic density during the closure cycle involved and $M$ is the duration from the beginning of $\mathrm{Ph} 3$ up to the zigzag moment.

As shown in Fig. 10, waiting queues at these 5 LXs are drawn with regard to the time moment of zigzag occurring. The red dash line indicates the $4^{\text {th }}$ second of $\mathrm{Ph} 4$. The blue dotted line is an auxiliary indicator to show the dispersion of the scatter points in the chart. It is worth noticing that for LX 55 (cf. Fig. 10a) and LX 69 (cf. Fig. 10b) which show quite high road traffic density, their waiting queue length is almost concentrated on the blue line and then the cluster of waiting queue length points of LX 2 (cf. Fig. 10c) is next, which shows a little bit of dispersion around the blue line. However, for LX 4 (cf. Fig. 10d) and LX 21 (cf. Fig. 10e) which show significantly low road traffic density, their waiting queue length points are extremely dispersive.

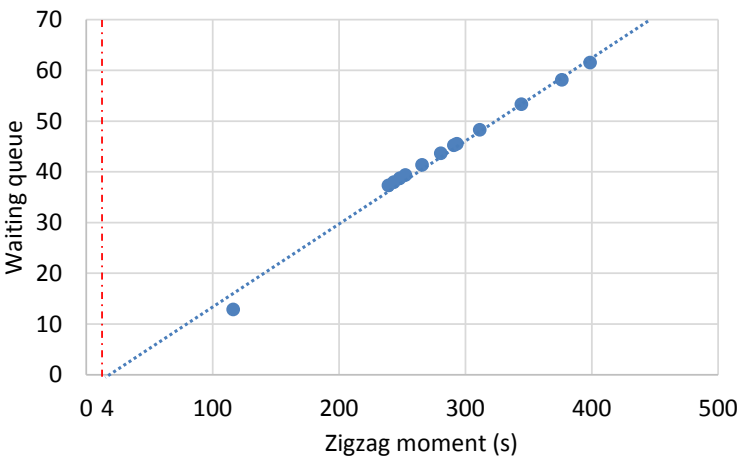

(a) The length of waiting queue at LX 55 in G1.

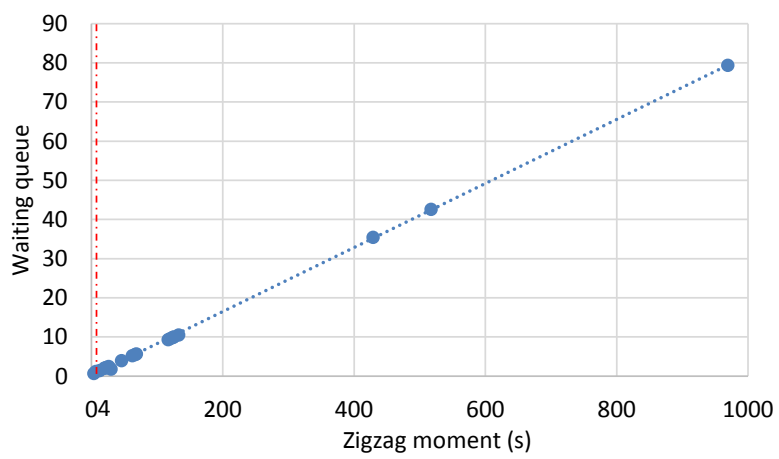

(b) The length of waiting queue at LX 69 in G1.

\footnotetext{
${ }^{2}$ according to statistics from SNCF Réseau
} 


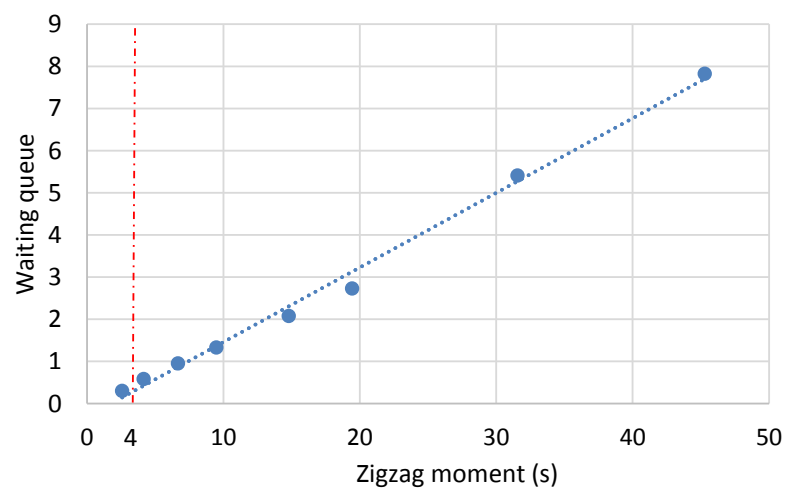

(c) The length of waiting queue at LX 2 in G2.

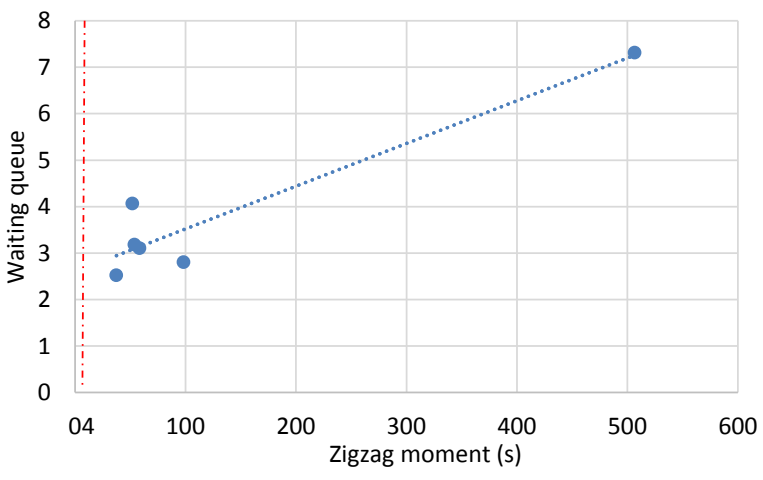

(d) The length of waiting queue at LX 4 in G3.

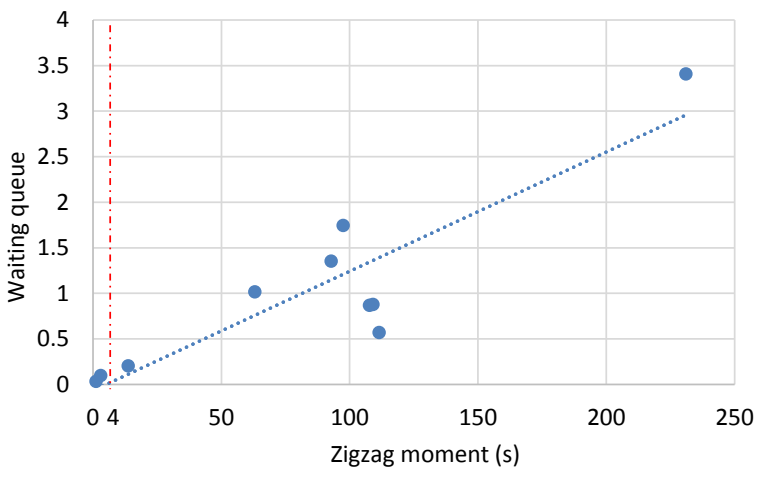

(e) The length of waiting queue at LX 21 in G3.

Fig. 10. The length of waiting queues at the 5 LXs.

One can point out that the troop crossing phenomenon is more noticeable at LX 55 and LX 69 than at the other LXs, due to the highest road traffic density at LX 55 and LX 69 among these LXs. Fig. 11 shows the time gap between two successive zigzagging vehicles during a same Ph4, respectively at LX 55 and LX 69. This observation is clearer in Fig. 11a, indeed, the first vehicle commits zigzag crossing after a long waiting time of $240 \mathrm{~s}$, and then the successive vehicles closely follow it to cross LX 55 as well. The average time gap between these following vehicles are $14 \mathrm{~s}$ and the shortest time gap is only about $4 \mathrm{~s}$. A similar phenomenon emerges at LX 69. There are 3 times of troop crossing just after the $1^{\text {st }}, 6^{\text {th }}$ and $10^{\text {th }}$ vehicles commit zigzag crossing (cf. Fig. 11b). Moreover, the troop crossing phenomenon at LX 55 is more remarkable than that at LX 69 mainly because the road traffic density at LX 55 is higher than that at LX 69. Therefore, the aforementioned facts indicate that the higher the road traffic density at an LX, the more likely the waiting queues occur and the distribution of waiting queue length is more inclined to a linear distribution with regard to the duration from the beginning of $\mathrm{Ph} 3$ up to the zigzag moment. Furthermore, the troop crossing phenomenon is inclined to occur at LXs with significantly high road traffic density and the higher the road traffic density, the more distinct the troop crossing phenomenon. 


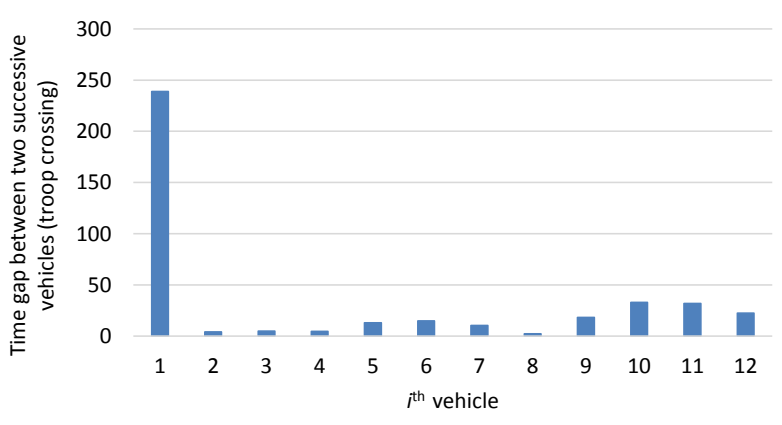

(a) Troop crossing phenomenon at LX 55 .

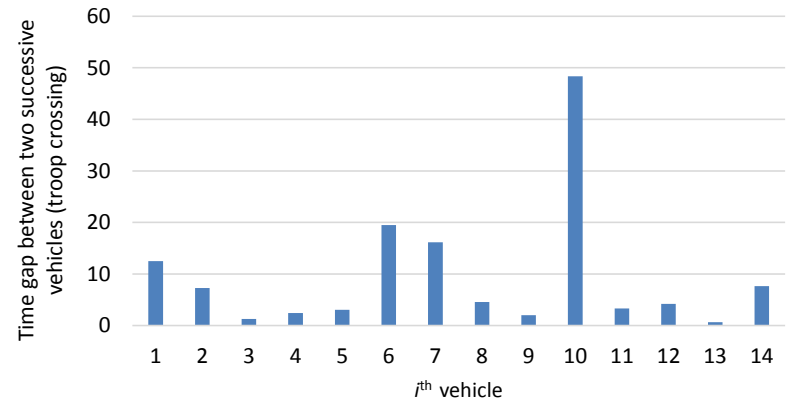

(b) Troop crossing phenomenon at LX 69.

Fig. 11. Troop crossing phenomenon at LX 55 and LX 69.

\section{Comparison of motorist responses to SAL2 and SAL4 LXs}

LX 425, an SAL4 LX, is taken into account in our field observation in order to compare motorist responses to SAL2 and SAL4 LXs. For the purpose of making the results more trustworthy, LX 356 and LX 2, which have the approximate road traffic density to that of LX 425 (differences less than 0.01), are selected for the comparison analysis in this section. The number of crossing vehicles during the closure cycle is analyzed to explore the trend of vehicle volume during various phases of the closure cycle. Since no zigzags are observed during $\mathrm{Ph} 4$ at LX 425 and due to the significant discrepancy of $\mathrm{Ph} 4$ durations from one closure cycle to another at each LX, only crossing vehicles during $\mathrm{Ph} 2$ and $\mathrm{Ph} 3$ are considered.

Turning to the data as shown in Table 3, the duration of $\mathrm{Ph} 2$ and $\mathrm{Ph} 3$ varies among the different LXs. The first 4 $\mathrm{s}$ of $\mathrm{Ph} 2$ is a special stage. The reason is explained as follows: when motorists observe the flashing lights and hear sirens, then, if it is possible to stop before the LX, they should brake. The reaction time, namely, the operating delay of the action guided by sense organs will take almost $1 \mathrm{~s}$, according to ergonomics studies (Green and Luce, 1967; Taylor et al., 1967; Welford, 1952). In addition, the longest braking coordination time of motorized vehicles does not exceed $0.8 \mathrm{~s}$. Then, the braking delay itself would be $2 \mathrm{~s}$ on average. Therefore, a vehicle crossing during the first 4 $\mathrm{s}$ of $\mathrm{Ph} 2$ will not be regarded as a violation in our study, only a vehicle crossing subsequently to the first $4 \mathrm{~s}$ of $\mathrm{Ph} 2$ should be considered as a violation, which may correspond to either an intentional violation or the inability of the motorist to stop his vehicle safely due to a high speed.

Therefore, as for the subsequent closure period after the first $4 \mathrm{~s}$ of $\mathrm{Ph} 2$, instead of considering the successive seconds in each phase ( $\mathrm{Ph} 2$ and $\mathrm{Ph} 3$ ), we divide $\mathrm{Ph} 2$ (resp. Ph3) into 2 (resp. 5) equal time intervals at each $\mathrm{LX}$ and then, we can make the analysis in terms of phase halves: $2^{\text {nd }}$ and $3^{\text {rd }}$ (resp. phase quintiles: $1^{\text {st }}, 2^{\text {nd }}, 3^{\text {rd }}, 4^{\text {th }}$ and $5^{\text {th }}$ ) in such a way as to be able to compare the road traffic volume in each time interval recorded at these LXs.

As shown in Fig. 12a, the number of vehicles crossing at the beginning of $\mathrm{Ph} 2$ at LX 425 is much bigger than that at LX 2 and LX 356. However, it decreases dramatically during the $2^{\text {nd }}$ stage of $\mathrm{Ph} 2$. The number of vehicles crossing in the $3^{\text {rd }}$ phase at LX 425 drops to the lowest among the 3 LXs. Moreover, one can notice that the scale of decrease at LX 425 is the biggest compared with the other SAL2 LXs.

Fig. 12b shows the normalized crossing ratio of vehicles during each phase of closure cycle at these 3 LXs. The normalized crossing ratio can eliminate the disparity of various road traffic densities at different LXs, which is expressed by Eq. (3).

$$
N C=N b_{V} / N b_{V T}
$$

where $N C$ represents the normalized crossing ratio during a time interval of the closure cycle at an $\mathrm{LX} ; N b_{V}$ is the number of crossing vehicles during the time interval considered, and $N b_{V T}$ is the total number of vehicles during the whole observation period at the LX considered. 


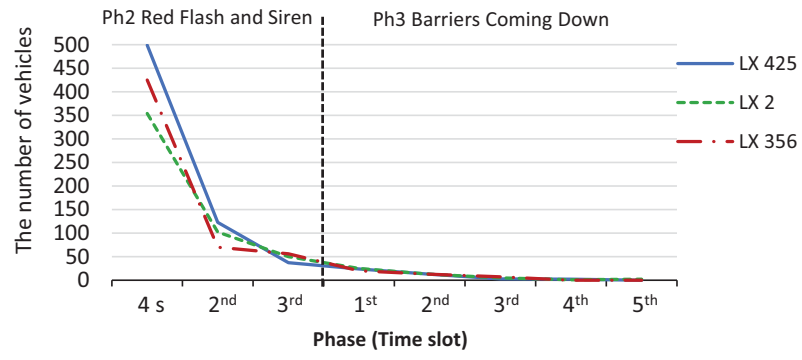

(a) The number of vehicles during each phase of closure cycle

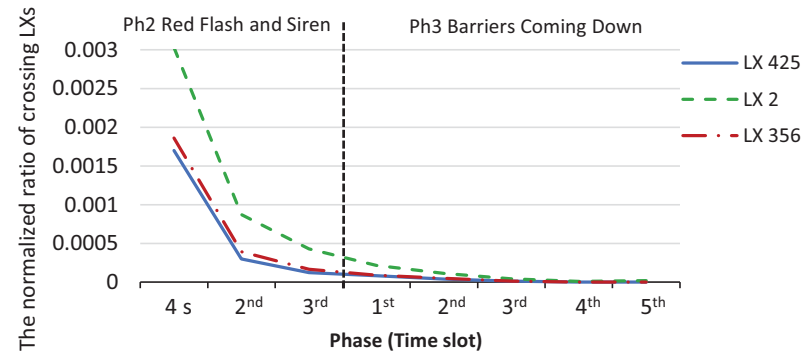

(b) The normalized crossing ratio of vehicles during each phase of closure cycle.

Fig. 12. Comparison of the number and normalized crossing ratio of vehicles at SAL2 and SAL4 LXs.

According to Fig. 12b, obviously, the normalized crossing ratio during the closure cycle at LX 425 is the lowest among the 3 LXs. This indicates that motorists are more cautious when encountering closure cycles at an SAL4 LX and they scarcely cross an SAL4 LX during closure cycles. In fact, four half barriers of an SAL4 LX act as physical separators in four quadrants to effectively prevent zigzag crossing from both opposite directions. Another reason for motorists scarcely crossing an SAL4 LX is that, motorists know clearly that if they are blocked in the intersection zone, they will not be able to escape from the closed SAL4 LX. In spite of these facts, we cannot arbitrarily state that SAL4 LXs are much safer than SAL2 LXs since the above new hazard of being blocked in the intersection zone is introduced by using SAL4 LXs. Therefore, further before/after measurements are still needed to assess the efficiency of SAL4 LXs.

\section{Discussion}

Based on the analysis of zigzag violations during $\mathrm{Ph} 4$ in section 3, we can summarize that the duration of $\mathrm{Ph} 4$, the existence of a nearby railway station and the road traffic density have significant impact on zigzag violations. It is recalled that during a prolonged $\mathrm{Ph} 4$, the longer the waiting time for vehicles, the lower the violation rate. This conclusion contradicts the general conjecture commonly assumed. Moreover, in terms of the global risk at a given LX, motorists are more likely to commit zigzag violations at the LX located close to a railway station. Indeed, the existence of a nearby railway station can foster the dispersion of $\mathrm{Ph} 4$ durations and, as illustrated earlier in the paper, the more dispersive the $\mathrm{Ph} 4$ durations at an LX, the higher the risk of zigzag violations at this LX.

Although the violation rate decreases as the time interval starting after the first $4 \mathrm{of} \mathrm{Ph} 4$ up to the violation moment prolongs, one cannot ignore the fact that the train-activated LX control system is susceptible to losing motorists' trust primarily due to variations in terms of $\mathrm{Ph} 4$ duration. Namely, it is possible for motorists to misunderstand the LX control system and commit zigzags when they have to wait for a long time without observing any train approaching, due to very slow train speed (e.g., they would think there is a failure in the LX control system, but it works well in fact). Reasonable and consistent warning time design is crucial to avoid zigzag violations during a long Ph4 (Ghazel, 2017). According to a report of FHWA (1991), motorists would accept a shorter clearance time at flashing lights and attempt to skirt barriers when the warning time exceeds 40-50 s. More importantly, second train coming active warning signs could help mitigate zigzag violations when $\mathrm{Ph} 4$ is prolonged by successive trains approaching. A short time gap between two successive approaching trains would cause a persistent closure of the LX after the first train has passed, since there is not enough time for LX control system to finish the activity of barriers uplifting before the second train arriving. Correspondingly, the $\mathrm{Ph} 4$ duration is prolonged by LX keeping closed. Such a kind of warning signs can avoid motorists losing patience when confronted with long LX closure cycles caused by successive approaching trains.

As for the impact of road traffic density, the higher the road traffic density at an LX, the more likely the waiting queue formation, hence, the troop crossing phenomenon is most likely to be boosted at LXs with significantly high road traffic density. In order to reduce the collision risk fostered by long waiting queues and troop crossing phenomenon, the installation of median separators and transforming SAL2 LXs into SAL4 LXs (Four-half barrier systems) (Ghazel and El-Koursi, 2014) or two-full barrier LXs (SAL2F) are two further solutions. 
In fact, a median separator (used with an additional "U-Turn" or "Z-Turn" prohibition sign) in front of an SAL2 LX acts as a physical separator between opposing lanes of road traffic. Such a device effectively prevents zigzag violations with a visual cue intended to impede crossing to the opposing traffic lane. As shown in Table 6, the average length of waiting queue at the $4^{\text {th }} \mathrm{s}$ of $\mathrm{Ph} 4$ at an SAL2 LX can be a preliminary guidance for designing the minimum length of a median separator at different LXs (the length of normal-size vehicle is considered: $3.8-4.3 \mathrm{~m}$ ). However, before/after measurements are still needed to assess the efficiency of such solutions.

Table 6. The length of waiting queue (the number of waiting vehicles) at the $4^{\text {th }} \mathrm{s}$ of $\mathrm{Ph} 4$ at each SAL2 LX.

\begin{tabular}{ll}
\hline LX & Waiting queue length at the $4^{\text {th }} \mathrm{s}$ of Ph4 \\
\hline LX 55 & 4.942 \\
LX 58 & 3.334 \\
LX 69 & 2.524 \\
LX 356 & 1.242 \\
LX 2 & 1.080 \\
LX 82 & 0.732 \\
LX 136 & 0.353 \\
LX 71 & 0.347 \\
LX 4 & 0.188 \\
LX 21 & 0.105 \\
\hline
\end{tabular}

According to the analysis in section 4, the SAL4 (or SAL2F) system is a significantly effective means to avoid zigzag violations of motorists. However, it is more costly than the other aforementioned technical solutions. Moreover, as mentioned in section 4, a new hazard will be introduced while using this device, that is vehicles could be trapped on the LX intersection zone in case of traffic jam when the four half (or two full) barriers come down. One solution would be to install additional obstacle detectors in order to reopen the exit barriers and order the train to brake. Such a protection system has been tested in the U.S. (Chadwick et al., 2014). Obstacle detectors should be intelligent enough to identify the difference between a car moving slowly and one that is stationary (Silmon and Roberts, 2010). Any stationary vehicle staying for a long enough time on the LX intersection track can be assumed to be in trouble. In addition, according to the return on experience related to various LX safety strategies implemented in some countries (Anandarao and Martland, 1998; ATC, 2010; Davey et al., 2005; Taylor, 2008; Wullems, 2011), a combination of education (aimed at changing road user behavior), enforcement and engineering measures is believed to lead to high safety level at LXs.

\section{Conclusions}

The present study offers a new perspective on motorist behavior during the closure cycles of LXs. The results obtained enable us to draw general conclusions and make recommendations for improving the whole LX safety. Ten SAL2 LXs and one SAL4 LX were selected for field measurement and the data regarding road traffic and railway traffic at these 11 LXs were collected during 9 weeks, then analyzed to derive the main features to characterize the behavior of motorists during LX closure cycles. The experimental equipment used in this study is at the same time reliable, practical, easy to install and economical. In summary, our ad-hoc installation is more convenient for our experiment, compared with cameras, automatic video surveillance or sophisticated video recording.

Although many existing studies have dealt with motorist behavior at LXs, such studies have not considered the separate phases of the LX closure cycle, particularly $\mathrm{Ph} 4$ "Barriers Down". Some recent studies adopted qualitative approaches for understanding motorist behavior during the entire cycle of LX control, including when the LX is open to road traffic. The main contributions of our study are that: thorough analyses on the impact of influential factors, i.e., the duration of $\mathrm{Ph} 4$, the LX location (railway station nearby or not) and the road traffic density, on zigzag violations during $\mathrm{Ph} 4$ are carried out. Namely, the violation rate, the waiting queue and the troop crossing phenomenon during $\mathrm{Ph} 4$ are quantitatively and finely analyzed with regard to the above influential factors. In fact, according to the field measurements we performed, the variability of $\mathrm{Ph} 4$ duration has a significant impact on the rate of violations. In the present study, such a variability is mainly due to the fact that the involved LXs are located close to a railway station. 
However, in general, stakeholders also need to pay attention to other operating conditions that may cause discrepancy in terms of LX closure duration, such as the mixture of different train types (passenger, freight, etc.), train speeds, etc. Moreover, the distinction of motorist responses to SAL2 and SAL4 LXs is scrutinized to determine the efficiency of SAL4 LXs in terms of preventing zigzag violations. Thus, corresponding targeted technical suggestions can be recommended according to the specific analysis results pertaining to $\mathrm{Ph} 4$, so as to improve LX safety. Such thorough and novel analyses are rarely presented in existing works.

In summary, the aforementioned contributions of this study respond to the key knowledge gap of risky motorist behavior at LXs with regard to separate phases during the LX closure cycle. Moreover, such analyses pave the way for identifying practical design measures and improvement recommendations to prevent LX accidents. In future works, we will investigate more influential factors and develop Bayesian risk models to quantify the causal relationships between these influential factors and the LX safety level.

\section{Acknowledgements}

This work has been in the framework of "MORIPAN project: MOdèle de RIsque pour les PAssages à Niveau" within the Railenium Technological Research Institute, in cooperation with the National Society of French Railway Networks (SNCF Réseau) and the French Institute of Science and Technology for Transport, Development and Networks (IFSTTAR).

\section{References}

Abraham, J., Datta, T., Datta, S., 1998. Driver behavior at rail-highway crossings. Transportation Research Record: Journal of the Transportation Research Board 1648, 28-34.

Anandarao, S., Martland, C.D., 1998. Level crossing safety on East Japan Railway Company: Application of probabilistic risk assessment techniques. Transportation 25 (3), 265-286.

ATC, 2010. National Railway Level Crossing Safety Strategy 2010-2020. Main Roads Western Australia, Australia.

Chadwick, S.G., Zhou, N., Saat, M.R., 2014. Highway-rail grade crossing safety challenges for shared operations of high-speed passenger and heavy freight rail in the US. Safety Science 68, 128-137.

Cooper, D.L., MacLeod, K.E., Ragland, D.R., 2007. Rail Crossings: A Strategy to Select Countermeasure Improvements for Rail-Highway Crossings in California. Transportation Research Board 2007 Annual Meeting, Washington, D.C.

Davey, J., Wallace, A., Stenson, N., Freeman, J., 2008. The experiences and perceptions of heavy vehicle drivers and train drivers of dangers at railway level crossings. Accident Analysis \& Prevention 40 (3), 1217-1222.

Davey, J., Ibrahim, N., Wallace, A., 2005. Motorist behaviour at railway level crossings: An exploratory study of train driver experience. In Proceedings of the Road Safety Research, Policing and Education Conference, Wellington, New Zealand.

European Railway Agency (ERA), 2014. Railway safety performance in the European Union. 9 (2) Agency Regulation, 881/2004/EC.

Evans, A.W., 2011. Fatal accidents at railway level crossings in Great Britain 1946-2009. Accident Analysis \& Prevention 43 (5), $1837-1845$.

FHWA, 1991. Warning time requirements at railroad-highway grade crossings with active traffic control. Report No. FHWA SA-91-007, Federal Highway Administration. Washington, DC: February 1991.

Ghazel, M., 2009. Using stochastic Petri nets for level-crossing collision risk assessment. IEEE Trans. on Intelligent Transportation Systems 10 (4), 668-677.

Ghazel, M., 2017. A Control Scheme for Automatic Level Crossings under the ERTMS/ETCS Level 2/3 Operation. IEEE Trans. on Intelligent Transportation Systems (online access).

Ghazel, M., El-Koursi, E.-M., 2014. Two-half-barrier level crossings versus four-half-barrier level crossings: A comparative risk analysis study. IEEE Trans. on Intelligent Transportation Systems 15 (3), 1123-1133.

Green, D.M., Luce, R.D., 1967. Detection of auditory signals presented at random times. Perception \& Psychophysics 2 (10), 441-450.

Khattak, A.J., 2009. Comparison of driver behavior at highway-railroad crossings in two cities. Transportation Research Record: Journal of the Transportation Research Board 2122, 72-77.

Larue, G.S., Rakotonirainy, A., Haworth, N. L., Darvell, M., 2015. Assessing driver acceptance of Intelligent Transport Systems in the context of railway level crossings. Transportation Research Part F: Traffic Psychology and Behaviour 30, 1-13.

Lenné, M.G., Rudin-Brown, C.M., Navarro, J., Edquist, J., Trotter, M., Tomasevic, N., 2011. Driver behaviour at rail level crossings: Responses to flashing lights, traffic signals and stop signs in simulated rural driving. Applied ergonomics 42 (4), 548-554.

Liang, C., Ghazel, M., Cazier, O., El-Koursi, E.-M., 2017. Risk analysis on level crossings using a causal Bayesian network based approach. Transportation Research Procedia 25, 2172-2186.

Liu, B., Ghazel, M., Toguyeni, A., 2016. Model-Based Diagnosis of Multi-Track Level Crossing Plants. IEEE Trans. on Intelligent Transportation Systems 17 (2), 546-556.

Mekki, A., Ghazel, M., Toguyeni, A., 2012. Validation of a new functional design of automatic protection systems at level crossings with modelchecking techniques. IEEE Trans. on Intelligent Transportation Systems 13 (2), 714-723.

G. Plesse, 2017. Des détecteurs d'obstacles déployés aux passages à niveau, France. From http://www.leparisien.fr/info-paris-ile-de-franceoise/transports/des-detecteurs-d-obstacles-deployes-aux-passages-a-niveau-02-06-2017-7011714.php 
Read, G.J., Salmon, P.M., Lenné, M.G., Stanton, N. A., 2016. Walking the line: Understanding pedestrian behaviour and risk at rail level crossings with cognitive work analysis. Applied ergonomics 53, 209-227.

Richards, S.H., Heathington, K.W., 1990. Assessment of warning time needs at railroad-highway grade crossings with active traffic control. Transportation Research Record: Journal of the Transportation Research Board 1254, 72-84.

Rudin-Brown, C. M., Lenné, M. G., Edquist, J., Navarro, J., 2012. Effectiveness of traffic light vs. boom barrier controls at road-rail level crossings: A simulator study. Accident Analysis \& Prevention, 45, 187-194.

Salmon, P.M., Read, G.J., Stanton, N.A., Lenné, M.G., 2013. The crash at Kerang: Investigating systemic and psychological factors leading to unintentional non-compliance at rail level crossings. Accident Analysis \& Prevention 50, 1278-1288.

Salmon, P.M., Lenné, M.G., Read, G.J. et al., 2016. More than meets the eye: Using cognitive work analysis to identify design requirements for future rail level crossing systems. Applied Ergonomics 53, 312-322.

San Kim, D., Yoon, W.C., 2013. An accident causation model for the railway industry: Application of the model to 80 rail accident investigation reports from the UK. Safety science $60,57-68$.

Shappel, S.A., Wiegmann, D.A., 2000. The human factors analysis and classification system-HFACS (No. DOT/FAA/AM-00/7). US Federal Aviation Administration, Office of Aviation Medicine.

Silmon, J., Roberts, C., 2010. Using functional analysis to determine the requirements for changes to critical systems: Railway level crossing case study. Reliability Engineering \& System Safety 95 (3), 216-225.

SNCF, 2015. Research on the material of level crossing in 2014, France.

SNCF Réseau, 2011. World Conference of Road Safety at Level Crossings (Journée Mondiale de Sécurité Routière aux Passages à Niveau), France. From http://www.planetoscope.com/automobile/1271-nombre-de-collisions-aux-passages-a-niveau-en-france.html

SNCF Réseau, 2015. 8th National Conference of Road Safety at Level Crossings (8ème Journée Nationale de Sécurité Routière aux Passages à Niveau), France. From http://www.sncf-reseau.fr/fr/dossier-de-presse-8eme-journee-nationale-de-securite-routiere-aux-passages-a-niveau

Stanton, N.A., Walker, G.H., 2011. Exploring the psychological factors involved in the Ladbroke Grove rail accident. Accident Analysis \& Prevention 43 (3), 1117-1127.

Stefanova, T., Burkhardt, J.-M., Filtness, A., Wullems, C., Rakotonirainy, A., Delhomme, P., 2015. Systems-based approach to investigate unsafe pedestrian behaviour at level crossings. Accident Analysis \& Prevention 81 (0), 167-186.

Taylor, M.M., Lindsay, P.H., Forbes, S.M., 1967. Quantification of shared capacity processing in auditory and visual discrimination. Acta Psychologica 27, 223-229.

Taylor, K., 2008. Addressing road user behavioural changes at railway level crossings. ACRS-Travelsafe National Conference, 368-375.

Tey, L.S., Ferreira, L., Wallace, A., 2011. Measuring driver responses at railway level crossings. Accident Analysis \& Prevention 43 (6), 2134-2141.

Ward, N.J., Wilde, G.J., 1995. Field observation of advance warning/advisory signage for passive railway crossings with restricted lateral sightline visibility: An experimental investigation. Accident Analysis \& Prevention 27 (2), 185-197.

Welford, A.T., 1952. The 'psychological refractory period' and the timing of highspeed performance-a review and a theory. British Journal of Psychology. General Section 43 (1), 2-19.

Wigglesworth, E.C., 2001. A human factors commentary on innovations at railroadhighway grade crossings in Australia. Journal of Safety Research 32 (3), 309-321.

Wilson, J.R., 2014. Fundamentals of systems ergonomics/human factors. Applied Ergonomics 45, 5-13.

Wilson, J.R., Norris, B.J., 2005. Rail human factors: Past, present and future. Applied Ergonomics 36, 649-660.

Wullems, C., 2011. Towards the adoption of low-cost rail level crossing warning devices in regional areas of Australia: A review of current technologies and reliability issues. Safety science 49 (8), 1059-1073.

Young, K. L., Lenné, M. G., Beanland, V., Salmon, P. M., Stanton, N. A., 2015. Where do novice and experienced drivers direct their attention on approach to urban rail level crossings. Accident Analysis \& Prevention, 77, 1-11. 